\title{
Cartografia dos caminhos de um usuário de serviços de saúde mental: produção de si e da cidade para desinstitucionalizar
}

| ${ }^{1}$ Maria de Nasaré Carvalho, ${ }^{2}$ Tulio Batista Franco |

Resumo: Com base na cartografia proposta neste estudo, procurou-se analisar a rede de cuidados à saúde mental, tomando um usuário como analisador dessa própria rede. A produção de dados se deu com observação do cenário de trabalho e cuidado, anotações em caderno de campo, acompanhamento do usuário e entrevistas com este e com seu principal cuidador. $\mathrm{O}$ achado do estudo que mais chama atenção é o fato de que o usuário é um grande protagonista na construção da sua rede, do seu cuidado, criando, a partir disso, novas possibilidades de existência e produzindo sua própria desinstitucionalização, levando a crer ser possível a construção de outras cidades no mundo da loucura.

> Palavras-chave: saúde mental; cuidado; cartografia; rede.

\author{
1 Universidade Federal \\ Fluminense. Mestrado em \\ Saúde Coletiva. Niterói-RJ, \\ Brasil. Endereço eletrônico: \\ nasareloureirocarvalho@ \\ hotmail.com \\ ${ }^{2}$ Universidade Federal \\ Fluminense. Planejamento \\ em Saúde. Niterói-RJ, \\ Brasil. Endereço eletrônico: \\ tuliofranco@gmail.com
}

Recebido em: 13/09/2014 Aprovado em: 17/04/2015 


\section{Introdução}

A palavra rede tem várias representações, e origina-se do latim retis, que demonstra um entrelaçamento, uma organização formal e não formal que possibilita dar vida aos processos sociais, construindo formas de conexão e flexibilidade às demandas produzidas. $\mathrm{O}$ conceito de rede como sistema de organização, por sua vez, provém da Biologia, e tem hoje importância fundamental na nossa sociedade, na qual podemos considerar "rede" um dispositivo social que ajuda o sujeito na sua vida produtiva e nas suas relaçōes. No entanto, o que significa pensar uma rede nos cenários de produção de cuidado na saúde mental?

Deleuze e Guattari, no livro Mil platôs (1995), abordam um tema da botânica, o rizoma, ${ }^{1}$ conceito que tentarei conectar com as redes e, ao mesmo tempo, com a loucura.

As redes em saúde são constituídas por vários atores. Podemos afirmar que existem características importantes na constituição dessa inter-relação, contexto que permite que se entendam tais relações como uma rede rizomática, trazendo para o campo relacional da saúde mental conexōes capazes de tentar construir uma rede de potencialidades e possibilidades de vida.

As conexões compõem o primeiro princípio de Deleuze e Guattari (1995), que afirmam que um ponto de um rizoma - e, por analogia, de uma rede - pode ser conectado a qualquer outro. Atualmente, porém, existe uma rede de cuidado presa à lógica burocrática, que acaba por direcionar os fluxos de cuidado em um único sentido, deixando de valorizar as necessidades particulares dos usuários. As redes se formam, em certo sentido, sobre uma suposta linha de cuidado que se dá nos projetos terapêuticos, isto é, no conjunto de atos pensados para resolver determinado problema de saúde de um usuário (FRANCO, 2006).

Assim, a rede rizomática propõe conexôes entre todos os lados, que mudam de acordo com os novos acontecimentos em vez de ficarem presas a definiçōes ou a modelos fechados. A construção de múltiplas entradas na rede de saúde mental faz com que o trabalhador e o usuário possam construir as suas conexões sustentados nas suas próprias ações, definidas pelo trabalho e pelas subjetividades.

O segundo princípio dos autores é o da heterogeneidade: um rizoma vai além das conexões e é atravessado por cadeias semióticas - sentidos, signos e sinais de 
toda natureza -, conectadas por modos de codificação muito diversos, entre eles cadeias biológicas, políticas, materiais, culturais e econômicas.

Segundo Franco (2006), uma rede rizomática pressupõe conexões com o diferente, pois o universo que articula o campo da saúde é heterogêneo, permeado por relações de poder e sistemas sociais de produção de subjetivações. Essa complexidade se expressa em diferentes modos de compreender a realidade e de nela atuar. A heterogeneidade desse universo pressupóe capacidade de convivência, pactuação, manejo de conflitos e alta capacidade de autoanálise, uma vez que é mais difícil e complexo lidar de forma produtiva com o diferente do que com o igual.

O terceiro princípio desses autores é o da multiplicidade, instância na qual não faz sentido falarmos em sujeito ou objeto. Trata-se aqui de grandezas e determinações que se expandem de acordo com os seus agenciamentos. Um agenciamento é precisamente esse crescimento das dimensões numa multiplicidade que muda necessariamente de natureza à medida que aumenta suas conexôes.

As redes, portanto, rompem com a ideia de unicidade - ou seja, de uma direção, um sujeito, uma diretriz etc. - articulam-se à noção de multiplicidade, o que pressupõe suportar diversas lógicas e operar sobre lógicas determinadas por representações simbólicas e por subjetividades que determinam as singularidades dos sujeitos. A loucura, da mesma forma, é múltipla em sua estrutura, o que a torna distante no momento em que, pelo seu delírio, tenta suportar toda a tensão provocada pelas conexões feitas em várias direçōes, operando nesse fluxo contínuo de possibilidades.

O quarto princípio de ruptura a-significante de Deleuze e Guattari (1995) explicita que um rizoma pode ser rompido em qualquer lugar e também retomado segundo uma ou outra das suas linhas e segundo outras linhas. A ruptura pode, muitas vezes, trazer algum sentido aos processos que se baseiam na ideia de equilíbrio permanente, permitindo que se entendam os entraves e os obstáculos como lugares de grande tensão e de explosão entre trabalhadores, usuários e instituição, proporcionando transformações na produção de cuidado na saúde.

Entende-se, portanto, conforme afirma Franco (2006), que uma ruptura em determinado lugar pode significar a abertura de linhas de fuga para outros 
sentidos, não previstos anteriormente, o que tem como significado uma alta capacidade de produzir-se a si mesmo, algo próprio das redes rizomáticas.

\section{Rede de Atenção Psicossocial e a rede rizomática na Saúde Mental}

Em 2011, o Ministério da Saúde cria a Rede de Atenção Psicossocial, que tem a atribuição de

[a] mpliar o acesso à atenção psicossocial da população em geral; promover o acesso das pessoas com transtornos mentais e com necessidades decorrentes do uso de crack, álcool e outras drogas e suas famílias aos pontos de atenção; e garantir a articulação e integração dos pontos de atenção das redes de saúde no território, qualificando o cuidado por meio do acolhimento, do acompanhamento contínuo e da atenção às urgências (BRASIL, 2011).

O tema da rede está na agenda dos serviços de saúde, e é um consenso nas diversas instâncias do SUS a ideia de que é necessário integrar todos os serviços e equipes no cuidado. No entanto, observa-se que há um protagonismo dos trabalhadores e usuários na constituição de redes. Isso nos informa que há uma rede formal e institucionalizada convivendo ao mesmo tempo com redes ad hoc, isto é, formadas para um fim específico, singulares, construídas em ato nas relaçôes de cuidado (MERHY et al., 2014).

Diante da questão acima, refletir sobre uma rede de atenção no universo da loucura é ao mesmo tempo desafiador e fascinante. O pressuposto de que partimos é o de que todos, trabalhadores e usuários, produzem redes no seu processo de trabalho (FRANCO, 2006), cabendo pensar que tipos de redes se organizam na produção do cuidado. Uma rede modular tradicional é uma possibilidade nos serviços de saúde. Por outro lado, a organização em rede a partir de múltiplas conexões e de fluxos contínuos, singulares, tenta exatamente romper com o modelo normativo, cuja aplicação, em alguns lugares, ainda acontece de forma hegemônica, em um cuidado centrado em procedimentos e medicamentalizado.

Outra questão importante é que, na prática, os autores que assumem as redes no cenário da produção de cuidado na saúde são capturados por sistemas normativos de significação da realidade e serializam as práticas de cuidado, quebrando a lógica das singularidades existentes no trabalhador e no usuário (FRANCO, 2006). Renunciar a um modelo tão enraizado pode gerar um 
resultado caótico entre os sujeitos; porém, trata-se de um momento rico para a invenção de outras formas de cuidar, livres de modelos a serem seguidos.

Segundo Franco (2006), por mais que as redes sejam hierarquizadas e regionalizadas, elas compõem um mapa que aos poucos se forma, como se as suas linhas navegassem sobre a realidade em uma alta intensidade de fluxos. Elas têm grande potencial de constituição do novo, um devir para os serviços de saúde associados ao cuidado e centrados nas necessidades dos usuários; espera-se que a sua forma de organização seja circular, com múltiplas entradas, baseada em tais necessidades. Os dispositivos de cuidado em saúde mental, por sua vez, devem se estruturar como agenciadores, com a finalidade de preservar e fortalecer os laços sociais através da lógica territorial.

A construção de uma rede é um processo coletivo, individual, estável, sensível, ativo e confiável. É um sistema dinâmico que gera progressivamente um novo mapa dos cuidados em saúde mental e que inclui serviços de natureza clínica - tais como Centros de Atenção Psicossocial Infanto-Juvenil (CAPSi), Centros de Atenção Psicossocial (CAPS), ambulatórios, hospitais, Equipes de Saúde da Família (ESFs), entre outros dispositivos -, além de outras formas que atravessam a vida de adultos, crianças e adolescentes: escola, família, amigos, igreja, órgãos da Justiça, instituições esportivas, de lazer e de cultura, associações de moradores, cooperativas, praças, clubes e a própria cidade - ou seja, tudo é possível no intuito de gerar encontros e direito à participação e à inclusão na sua comunidade.

\section{Metodologia}

O objetivo deste estudo é cartografar a produção de cuidado na rede de saúde mental, utilizando como campo de estudo um CAPS de um município de médio porte no estado do Rio de Janeiro, bem como todas suas conexôes da rede de cuidados.

Uma das bases para construção da pesquisa será a cartografia do cuidado a um usuário. Partimos do pressuposto de que o cuidado se realiza com base em encontros que se estabelecem entre os trabalhadores e destes com os usuários, indo além das relações específicas do serviço de saúde, porque pode ganhar a própria comunidade. As relações do encontro são intercessoras (MERHY, 2002) entre os que se encontram, ou seja, há um protagonismo mútuo, do trabalhador 
e do usuário, na produção do cuidado. O usuário, na sua capacidade produtiva, também está em análise.

Formulada por Gilles Deleuze e Félix Guattari, a metodologia da cartografia é reconhecida como uma forma de produzir conhecimento, a qual visa acompanhar um processo em vez de representar um objeto. Para tratar do assunto, é necessário trazer à tona o conceito botânico de rizoma utilizado pelos autores em Mil platôs (1995) para examinar o campo das produçóes sociais como um sistema aberto, heterogêneo e múltiplo de conexões, produzindo metamorfoses e cadeias semióticas e promovendo agenciamentos das diferenças em um campo de intensidades. Conforme os autores afirmam:

Num rizoma, ao contrário, cada traço não remete necessariamente a um traço linguístico: cadeias semióticas de toda natureza são aí conectadas a modos de codificação muito diversos, cadeias biológicas, políticas, econômicas etc., colocando em jogo não somente regimes de signos diferentes, mas também estatutos de estados de coisas. [...] Um rizoma não cessaria de conectar cadeias semióticas, organizações de poder, ocorrências que remetem [...] às lutas sociais. (DELEUZE; GUATTARI, 1995, p. 15).

Rolnik (2007), em Cartografia Sentimental, diz o seguinte: “[...] não é possível definir seu método (nem no sentido de referência teórica, nem no de procedimento técnico), mas apenas sua sensibilidade” (p. 67). Tal conclusão é esperada quando a proposta é mergulhar em territórios não apenas geográficos como existenciais, ou seja, encontros de corpos onde a sensibilidade das partes será sempre afetada. A autora elabora um "manual” do cartógrafo para direcionálo na sua pesquisa.

Kastrup (2007), por sua vez, define em linhas gerais que a cartografia é utilizada em pesquisas de campo no estudo da subjetividade e se afasta do objetivo de definir regras a serem aplicadas. Todavia, sua construção pode estabelecer algumas pistas com o objetivo de descrever, discutir e, sobretudo, coletivizar a experiência do cartógrafo.

Características importantes do cartógrafo são: acompanhar as linhas que se traçam, marcar os pontos de ruptura e de enrijecimento e analisar os cruzamentos dessas linhas heterogêneas. Pensar no protagonista da minha pesquisa é mergulhar no seu mundo, é tentar desenhar o mapa dos percursos percorridos em virtude da sua condição patológica e identificar quais os sentidos produzidos nessa trajetória, bem como os distintos caminhos constituídos pelas redes sociais, afetivas e 
institucionais. Sabemos que, por conta da existência do sofrimento, o caos e a reorganização, a ruptura e as conexôes são presentes em sua geografia existencial.

Rolnik (2007) sugere um modo de olhar além do enxergar, que vibre, que crie tensão e fluxos de intensidade e que mergulhe na geografia dos afetos, criando pontes possíveis de linguagem.

Será um desafio cartografar a rede de saúde mental junto a um usuário. Talvez não sejam encontradas muitas respostas para as questões presentes atualmente na produção de cuidado. Essa, todavia, não é a principal intenção, mas sim a proposta de acompanhar, no que diz respeito ao cuidado, os movimentos e as suas mutações.

É isso o que me parece interessante nas vidas: os buracos que comportam, as lacunas - às vezes dramáticos, às vezes nem tanto. Catalepsias ou uma espécie de sonambulismo por vários anos: muitas vidas comportam esse tipo de coisa. É talvez nesses buracos que se faz o movimento. (DELEUZE apud ROLNIK, 2007, p. 81).

Os dados foram produzidos de forma implicada pelos pesquisadores e tomando a experiência do ato de pesquisar como elemento importante no desenvolvimento da pesquisa. Foi significativo para a produção dos dados, o caminhar nos serviços, as relações com a equipe e com o usuário, um território a principio estranho, mas ao mesmo tempo fascinante. Deixar-se impregnar, encharcar da experiência nesses contextos, contribui para perceber, enquanto se produz os dados da cartografia, o quanto foi produtivo receber as informações e acompanhar os processos da rede na produção do cuidado com os usuários. A cartografia é uma vivência na qual aquele que pesquisa se sente misturado e envolvido na experiência existencial que ela proporciona, na produção do conhecimento. O cartógrafo é um pesquisador implicado, sendo também parte da experiência. Como tal, ele também se modifica no processo de pesquisa. Há uma produção do mundo e de si ao mesmo tempo.

A análise dos dados foi construída tendo como questão central os movimentos dos usuários, na sua relação com os trabalhadores e a institucionalidade. Não se estabeleceram categorias analíticas a priori, mas sim no processo de desenvolvimento da pesquisa e na medida em que esta foi desvelando o modo de construção de redes, os fluxos de conexão entre usuário e suas representações de cidade, a ruptura com a normativa institucional. Esses foram os principais marcadores através dos quais se buscou montar um entendimento das complexas questôes que envolvem o cuidado em rede na atenção psicossocial. 
Vamos começar a mergulhar na história de Teutônico (nome fictício), que será, daqui pra frente, uma presença que irá se integrando ao nosso corpo sensível, tornando-se parte de nós.

Sua história foi transmitida em uma reunião de equipe do CAPS, a qual envolvia também a equipe da residência terapêutica, dispositivo de cuidado no qual ele estava inserido. Foi nessa situação que foi possível conhecer esse usuário, sua história, seu ingresso no serviço de saúde mental, seu modo de vida e a forma como ele mesmo produzia sua existência. Enfim, percebeu-se todo contexto no qual ele vivia e sua relação com os serviços.

O cuidado ao usuário tinha certa complexidade para a rede de saúde mental. Por ser muito dinâmico e produtivo, assumia um protagonismo na condução da sua vida, o que não era comum de se ver nos serviços de saúde mental. Quem o apresentava era sua psicóloga de referência no CAPS, a quem daremos o nome fictício de Hanah.

A equipe da residência terapêutica estava presente na reunião para escutar sobre o desenvolvimento do usuário no CAPS. Os relatos eram transmitidos pela psicóloga que o assistia. Na ocasião, a equipe estava também pedindo ajuda no cuidado ao usuário, pois tinha dificuldades com seu comportamento transgressor às regras de convivência na residência. Embora ele tenha certa autonomia na produção do seu modo de viver, o que lhe permite "se virar" bem na vida, também "se enrola" ao contrair dívidas e se relacionar com várias mulheres, por vezes usa drogas de uma maneira que lhe expõe, tem atitudes evasivas com as crianças da comunidade e com as cuidadoras da residência terapêutica.

A equipe da residência terapêutica considera esses comportamentos desafiadores e comprometedores em relação a Teutônico, à comunidade em que ele vive, e à equipe de cuidadores da residência terapêutica. Tais comportamentos acabam envolvendo a comunidade e os demais usuários inseridos na residência. São situações bem complicadas, segundo a equipe, tanto para Teutônico como para o projeto em si, pois seu comportamento cria tensóes com a comunidade, em especial o tráfico de drogas ali presente. É uma pessoa que tenta se livrar de qualquer julgamento, certo ou errado. Segundo ele mesmo, é o "Rei Teutônico", que sempre procurou meios de burlar e manipular a sua própria 
institucionalização. Sua relação com a equipe é tensa, pois com Teutônico tudo

pode acontecer. Isso parece ser uma visão da equipe, pois, segundo ele, "está tudo bem", e o que acontece são "fofocas". Como não gosta muito de cumprir as regras estabelecidas na residência, nega as acusações. Foi institucionalizado por mais de 10 anos, passou por todo processo de desinstitucionalização e caminhou até a inserção em uma residência terapêutica. Seu prontuário informava:

Teutônico está com 58 anos, é natural do Mato Grosso do Sul, solteiro, tem uma filha, estudou até a quinta série do antigo primário, mora atualmente em uma residência terapêutica. Esteve internado na Casa de Saúde de 1995 a 2005, seu diagnóstico é de esquizofrenia residual (F 20.5). É aposentado pelo benefício de volta para casa. Sua entrada no serviço do CAPS aconteceu em 15/03/2006. Não tem familiares, apenas pode contar com a equipe do CAPS e a equipe da residência terapêutica.

Teutônico um dia sumiu de casa, ficando por dois anos desaparecido. Um dia foi encontrado por um amigo do quartel como mendigo, encontrava-se em péssimo estado de higiene e com feridas pelo corpo. Desde então iniciou suas internaçôes.

Em junho de 2005, teve alta da Casa de Saúde e foi transferido para outra Casa de Saúde. Houve todo um trabalho da equipe do CAPS no processo de desinstitucionalização de Teutônico. (Dados retirados do prontuário do CAPS sobre Teutônico)

Traremos neste trabalho algumas falas de Teutônico e percepções de Hanah. Incluiremos esses dados por verificarmos muita intensidade e potência na relação que se estabeleceu entre o usuário e os cuidadores. Adotamos como ponto de partida para a produção do cuidado as intercessões construídas entre eles, usuário e seus cuidadores de referência.

Teutônicoiniciouacompanhamento no CAPSem marçode2006, encaminhado pela equipe de supervisão responsável pelo processo de desinstitucionalização de alguns usuários que pertenciam a clínicas e hospitais conveniados do SUS. Na época, encontrava-se internado em um hospital psiquiátrico, em condições de alta hospitalar, porém sem referência familiar. Sua mãe, único familiar de referência, falecera durante o período de internação, o que fez com que sua permanência no hospital psiquiátrico se prolongasse por 10 anos.

Desde que iniciou tratamento no CAPS, morou em diversos "quartinhos". Não conseguiu, porém, permanecer em nenhum, por não respeitar as regras estabelecidas pelos proprietários, levando prostitutas para o quarto e brigando constantemente com os outros moradores. Depois de se aborrecer com uma técnica do CAPS, resolveu ir a São Paulo sem dar notícias. Permaneceu lá durante oito meses como mendigo e depois retornou. 
Ao voltar, foi internado e permaneceu por um ano no Hospital Psiquiátrico. Durante esse tempo, Teutônico comparecia três vezes na semana ao CAPS e tinha como atividade a digitação de suas poesias no computador, pois percebíamos que as poesias possuíam um efeito organizador sobre ele.

A poesia é uma de suas maneiras de criar vínculos com as pessoas, técnicos ou usuários. Ele faz questão de usar o recurso da rima, mesmo que precise criar um novo sentido para suas frases.

Retiramos junto com o usuário seus documentos depois da alta, quando passou a morar na Residência Terapêutica, comparecendo também todos os dias ao CAPS, o que se sustenta até hoje.

A rua é seu espaço por excelência. Ao falar dela, diz: "vou dar uma volta na maçã̄. Mostra lugares onde permaneceu, como o presídio, por exemplo. Mostra pessoas conhecidas e também utiliza do seu humor com elas. Apresentou-me para o segurança do banco como sua psicóloga; quando este diz que sabe quem sou, ele responde: "ela tem cara de psicóloga né? E eu de maluco".

É na rua que diz: "Hanah, você não tem ideia do mundo de coisas que tem para comprar". Antes de algumas de suas saídas, costumamos conversar sobre o que irá comprar; no retorno para o CAPS, ele compra tudo diferente do combinado. Foram inúmeras as vezes em que trouxe presentes para mim. Desde brincos, batom, pulseiras, estojo, doces, potes, prendedores de cabelo etc. Se ouso recusar, ele diz: "você vai fazer essa desfeita?". Procuro localizar a cada vez o que representa seu movimento, sem aceitar de forma automática os presentes.

Percebo que ser cuidador fornece um lugar a ele, o que não aparece apenas na relação comigo. Porém, nessa função de cuidar, também se enrola. Às vezes, ele parece invadido por tantas ofertas que a rua apresenta nos camelôs e lojas. O que digo a ele nesses momentos é que as coisas continuarão lá e ele pode escolher o que vai comprar aos poucos. Ele me interroga: "o que você quer dizer quando diz que eu posso escolher? Por exemplo: escolher alguma coisa no supermercado?”.

A residência terapêutica é outro espaço no qual Teutônico produz a sua vida. De lá, tem o hábito de ligar para o CAPS para buscar solução para pequenos problemas do cotidiano: "Hanah, comi miojo e minha barriga tá cheia (sic)". Ou "a tampa do DVD não está abrindo".

Demonstra autonomia para resolver questôes de limpeza e divisão de tarefas domésticas na residência. Um ponto difícil que persiste é a sua relação com a 
vizinhança e com as crianças. As reclamações dos vizinhos continuam. Esse é um

ponto de dificuldade que encontramos.

\section{Discussão}

\section{Teutônico, seus platôs e a produção de uma cidade-rede}

Teutônico transformou a cidade em possibilidades de construir platôs. Segundo Deleuze e Guattari (1995), o que constitui os platôs são zonas de intensidade contínua que produzem territórios. Essa aproximação com a cidade aumenta a possibilidade de Teutônico de se abrir para vida coletiva, com condições de interagir com outras pessoas, estabelecer um espaço de relações de poder e de trocas. Dessa forma, ele tenta construir um platô de transformações e de vínculos.

A atividade de pesquisa foi também exercício de uma "clínica peripatética" (LANCETTI, 2007). Foi caminhando com Teutônico que seu mundo foi sendo desvelado, possibilitando perceber a importante produção de uma rede, que tinha na sua constituição o seu próprio protagonismo. Teutônico construiu uma cidade para si, dentro da cidade, o que só foi possível constatar acompanhando-o.

Acompanho Teutônico em alguns dos seus platôs. Fomos à biblioteca municipal, onde ele foi meu guia. $\mathrm{O}$ rapaz do setor de audiovisual o conhecia e Teutônico nos apresentou. Esse platô já faz parte do seu território existencial. Fomos para sessão de psicologia. Ele pega o livro A psicanálise do fogo e leva até o setor de empréstimo de livros. Ele já conhece as normas de empréstimo.

Minhas impressões sobre Teutônico vão ao encontro da proposta de discutir as redes na perspectiva de uma rede singular, construída por ele na cidade e em conexão com o serviço de saúde mental. Teutônico, em sua forma de ser e estar no mundo, se assemelha a um rizoma. Em suas relações, ele tenta efetuar conexões e fluxos entre os platôs - o primeiro princípio da rede rizomática. Não se fecha a modelos, buscando conexões para estar na vida.

Ele é heterogêneo, atravessado por sua cadeia semiótica, e múltiplo, pois à medida que faz novas conexões, há um apoderamento dos seus trajetos e uma busca por novas pactuaçôes com a equipe. Um rizoma pode se romper, e Teutônico rompe as regras, mas retoma em outro lugar: uma forma de vida produzida por ele mesmo. A ruptura pode dar outros sentidos para ele, linhas de fuga que resignificam seu modo de andar a vida, especialmente saindo da 
institucionalidade que o incomoda e produzindo nesse movimento novas conexões que dão sentido à sua existência.

Mais um platô: no caminho ele faz perguntas sobre minha vida, respondo-as e entramos no banco. Ele saca dinheiro e diz que não voltará para o CAPS, que precisa comprar seu cigarro no camelô, perto do terminal rodoviário; dá-me seu cartão do banco e me pede que o entregue para Hanah no CAPS: "Diga para Hanah que fui passear no bosque. Vou comprar cigarros, você quer ir comigo?”.

Ele quer mostrar a cidade onde mora. Pergunta se já conheço o parque da cidade; digo que sim e que gosto muito daquele lugar. Teutônico, apesar de tanto tempo institucionalizado, demonstra em suas atitudes que sua alma estava liberta das amarras do processo de institucionalização, onde a apropriação da vida do outro é imperiosa. Ele não se constitui de territórios fechados, pela sua heterogeneidade: mesmo dentro da instituição, buscava formas de burlar, manipular e atribuir a si mesmo poder em relação aos outros usuários.

Teutônico não poderá mais ficar na residência terapêutica, pois voltou a ter comportamentos evasivos dentro da comunidade. A equipe da residência terapêutica reuniu-se novamente com o CAPS e colocou em questão a situação da segurança, pois o comportamento de Teutônico provoca muitos conflitos na comunidade, e a preocupação da equipe é arriscar o projeto e a vida de Teutônico. Teutônico terá que voltar a morar em um quarto.

Após esse episódio, ao chegar ao CAPS, encontro Teutônico deitado no sofá, apático. Não parecia aquele homem falante, vibrante e dinâmico. Teutônico ficou quieto e depois do almoço foi embora. Ele rompe com a residência terapêutica por não aceitar ficar durante um período na emergência do hospital psiquiátrico, recomendação feita pela própria equipe do serviço por conta do risco que ele estava correndo em continuar na comunidade onde a residência estava inserida. Ninguém sabia para onde ele teria ido.

Depois de certo período ele ligou para Hanah dizendo que estava em São Paulo e que queria conversar um pouco com ela. Foi aí que decidiram um encontro, mas ela lhe diz que não poderia ir a São Paulo, então marcam em frente à Biblioteca Municipal da cidade, um dos platôs de Teutônico, mas ele não foi ao encontro. Quando Hanah retorna para o CAPS nesse mesmo dia, ele estava lá. Voltou a frequentar diariamente o CAPS e passou a morar em um quarto alugado por ele mesmo. Não pediu ajuda a ninguém. 
Depois dessa situação, voltei ao CAPS e encontrei com Teutônico. Já havíamos combinado anteriormente que iríamos sair para um passeio. Estávamos aguardando Hanah. Ele queria escrever um poema pelo Dia Internacional da Mulher e queria ligar o computador. Insistiu nisso até conseguir.

No caminho, foi possível assistir à sua integração com a cidade. Parava para conversar com alguns vendedores ambulantes, pedia as pessoas para acenderem seu cigarro. Um ambulante falava o seu nome como se os dois fossem velhos conhecidos. Ele tenta parar o trânsito para que eu e Hanah possamos atravessar fora do sinal, e as pessoas prestam atenção nesse homem solto pela cidade: é muito interessante e bonito assistir a todas essas cenas!

Ele nos convida a tomar uma água bem gelada, convite que aceitamos. Ele entra na Delegacia de Polícia e vai até o bebedouro e tomamos a prometida água gelada. Questionamos se é habitual ele beber água todos os dias naquele local e ele responde que sim: outro ponto de conexão com a cidade.

\section{O cuidado ao usuário e suas possibilidades}

Há uma dinâmica que se estabelece no processo das relações e em seus desdobramentos; noto que as redes e as formas de cuidar se sustentam nas relações entre os sujeitos. É nesse campo que as produções subjetivas tomam potência nos entrelaçamentos individuais e sociais, trazendo um suporte de interação com outras pessoas, produzindo atenção, acolhimento e cuidado. No entanto, há também potencialidades produzidas que trazem certa resistência nesse campo do cuidado.

O trabalho em saúde se dá a partir de encontros entre trabalhadores e usuários, isto é, são fluxos permanentes entre sujeitos. Esses fluxos são operativos, políticos, comunicacionais, simbólicos, subjetivos e formam uma rede de relaçōes a partir da qual os produtos referentes ao cuidado se estabelecem (FRANCO, 2006). Assim, as pessoas devem ser cuidadas como sujeitos, na singularidade de sua vida, seus devires, sua história, seus anseios, conflitos e delírios, sem tentar enquadrá-las, organizá-las em uma estrutura rígida, burocrática, centrada apenas nos sintomas.

Nosso personagem desdobra-se em muitos territórios, promovendo encontros a partir dos quais podemos perceber que é dessa forma que ele expressa seus afetos e é afetado por aquilo com o que se encontra. Talvez o que mais importe é que para ele seja possível passar pelos atravessamentos das situações cotidianas de sua vida. 
Há muitos Teutônicos em um só, ou seja, ele forma uma multiplicidade, na medida em que se apresenta como singularidade em cada situação com que se encontra na produção subjetiva da "sua" cidade. Teutônico, em sua intensidade para vida, traz para si inúmeros cenários, nos quais veste diferentes "máscaras"2, que simulam modos diferentes de ser e agir sobre o mundo a partir do qual ele produz seu modo de existência. Uma face sensível, capaz de conquistar torcida, outra face transgressora das regras da residência terapêutica e na comunidade. Ele nos coloca frente às nossas próprias máscaras, os muitos seres que há em nós e se expressam nas relações de cotidiano. No caso de Teutônico, as múltiplas máscaras são visíveis.

Teutônico está sendo acompanhado pelo CAPS desde 2006, na época, já estava em processo de alta da Casa de Saúde. Atualmente, tem uma psicóloga que é sua referência no CAPS, mencionada neste trabalho. Ela, hoje, tem a responsabilidade de acompanhar e cuidar de Teutônico.

[...] O projeto terapêutico não apenas do Teutônico, mas de qualquer usuário, é passível de mudanças ao longo do tempo de tratamento, e o que é determinante para isso, a meu ver, são as dicas que o próprio usuário fornece em relação a como se posiciona na vida e com as outras pessoas. Teutônico começou o tratamento no CAPS aproximadamente em 2005. Desde aquela época, a estratégia de que a equipe lança mão para se dirigir a ele tem variado de forma importante. Antes de frequentar assiduamente o CAPS, Teutônico estava institucionalizado em um hospital conveniado do SUS. Quando passou a se relacionar com as pessoas do lado de fora do hospital e a construir novos vínculos, no CAPS e na cidade, sua alta foi realizada. Atualmente, o nosso combinado em relação ao seu projeto terapêutico é que ele vá ao CAPS todos os dias. Os combinados precisam ser atualizados a cada vez. (Psicóloga de referência de Teutônico no CAPS).

A construção da rede de cuidado de Teutônico vai se desenhando por ele mesmo, pelas suas atitudes e pelas várias formas de agir, dos combinados que faz e ao mesmo tempo tenta burlar, das negociações com a equipe, das transgressões na comunidade onde morava, das suas produçōes poéticas, da construção de platôs, dos vínculos, de sua autonomia, da sua vida financeira etc. Ele é o protagonista do seu próprio cuidar e os profissionais são atores coadjuvantes, que às vezes assumem a máscara de "vigilantes" para que o próprio não "se perca totalmente”. Na minha percepção, a trajetória de Teutônico desenha uma protagonização: mesmo aquele que vive um sofrimento pode não perder o desejo e o encantamento pela vida e sua capacidade de produção, construindo conexões e novas histórias. 
Nesse caso, podemos pensar que a função que o cuidador tem na vida de Teutônico está diretamente relacionada com o lugar em que ele coloca esse cuidador, e que não se pode precisar exatamente, mas do qual temos como ter notícias ou sinais. É a partir desse lugar com Hanah que a construção do vínculo foi possível.

Traremos para nossa discussão as afecções que Espinosa propõe com o encontro dos corpos: existe na relação de usuário e profissional um campo de fluxos que produz afetividade. $\mathrm{O}$ trabalho afetivo atua nas relações de forma subjetiva, produzindo o desejo de estar nesse lugar de cuidador. O encontro de Teutônico e Hanah produz um campo potente no agir deles.

Deleuze (2002), citando Espinosa, destaca que, quando encontramos um corpo exterior que não convém ao nosso, tudo ocorre como se a potência desse corpo se opusesse à nossa potência, operando uma subtração: dizemos, nesse caso, que a nossa potência de agir é diminuída ou impedida, e que as paixões correspondentes são de tristeza. Mas, ao contrário, quando encontramos um corpo que convém à nossa natureza e cuja relação se compóe com a nossa, dizemos que sua potência se adiciona à nossa: as paixões que nos afetam são de alegria, nossa potência de agir é ampliada.

A cartografia revela nas relações as subjetividades que atravessam a produção desejante. Traz o contraditório, o inesperado, os desvios, o criativo, os estranhamentos e busca o alargamento do campo visual sobre os territórios existentes.

Hoje, Teutônico encontrou uma forma para se relacionar com os profissionais e com os usuários e foi incluindo as pessoas em suas poesias. Em outros momentos, discute com alguns funcionários, como os do apoio, pois quer transgredir certas regras de convivência na comunidade de usuários.

Os trabalhadores da saúde mental devem estar atentos aos seus encaminhamentos no cuidado com o usuário, pois hoje se usa muito o dispositivo de acolhimento, capaz de contribuir para questôes que envolvem o cuidar na saúde. Sabemos do seu poderoso processo no início das relaçôes do cuidado, priorizando as tecnologias relacionais; mas, em muitos serviços, o acolhimento vira uma repetição de práticas como a de triagem, burocrática e excludente. $\mathrm{O}$ acolhimento e o vínculo com responsabilização dependem sempre do profissional de saúde, assim como o rompimento com práticas manicomiais envolve muito além de um saber. Ele requer desterritorialização de um modo de fazer o 
cuidado que torna o usuário um objeto, em prol de outros que o reconheçam o protagonismo como singularidade, com capacidade de produção subjetiva.

É no encontro do trabalhador com o usuário que o acesso acontece ou não como dispositivo de cuidado, e o que define isso é o olhar sensível, o gesto acolhedor, o vínculo que se estabelece entre ambos, associados à ação interessada, no terreno da micropolítica, no cenário de produção do cuidado (FRANCO, ANDRADE; FERREIRA, 2009):

[...] o meu cuidar está relacionado também em fazer rede quando necessário, isto é, articular as ações do CAPS com o hospital psiquiátrico, com a sua moradia etc, avisada que há uma direção única de trabalho dentro de uma equipe, embora cada um possua o seu manejo singular. (Psicóloga de Teutônico no CAPS)

Teutônico produziu uma cidade pra si, dentro da cidade, com base nos muitos pontos de conexão que construiu, o que o salvou de uma institucionalização normativa e regulada. Seus platôs foram principalmente a Biblioteca Municipal, o banco onde faz a retirada semanal de sua aposentadoria, as ruas do Centro, o camelô onde compra seus cigarros, a Delegacia, os jardins, a praia (onde era localizada sua residência) e a própria comunidade onde esta estava inserida, e a unidade de atendimento. $\mathrm{O}$ trabalho da equipe, nesse caso, foi de acompanhar, orientar e observar Teutônico nessas construções de rede.

Trabalhar com a ideia de redes rizomáticas de Deleuze \& Guattari (1995) no contexto das relações no processo de trabalho em saúde é poder experimentar a possibilidade de potencializar no campo da saúde as várias formas de cuidar e ser cuidado (FRANCO, 2006).

[...] A rede que ele formou, ou está formando, está além da rede da saúde mental. Nem posso dizer que são todos que compóem sua rede, pois têm pessoas que ficariam de fora, já que ele se relaciona de alguma forma com muitas pessoas e algumas nem conhecemos, já que muitos dos seus trajetos realiza sozinho. Como ele diz, "sou de muitos lugares, não sou de lugar nenhum”. (Psicóloga de referência de Teutônico).

[...] Afirmamos algumas pessoas que são da sua rede: o senhor que lhe vende cigarro no camelô, que é sempre o mesmo, o gerente do banco, bancários, as mulheres do prostíbulo que frequenta, o vendedor da papelaria que é seu amigo, a funcionária da biblioteca pública, o rapaz que faz os carimbos, a própria instituição da polícia, o hospital, dentre outros lugares e pessoas. (Psicóloga de referência de Teutônico).

Imaginar como rizomáticas as redes que operam nos processos de trabalho, significa pensá-las como algo que opera além de linhas de cuidado que dão 
seguimento a itinerários terapêuticos, que atravessam determinada equipe ou unidade de saúde, encontrando-se com pontos de conexão na comunidade. Essa imagem expressa a ideia geral de múltiplas conexôes, realizadas fora de um eixo estruturante, reconhecendo o protagonismo do usuário na produção de conexões e fluxos. Assim, imaginamos que as redes rizomáticas combinam com a ideia de um serviço de saúde centrado na ética do cuidado, operando as tecnologias relacionais como o centro nevrálgico da atividade produtiva (FRANCO, 2006).

Essa experiência em sair com Teutônico pela cidade foi muito rica, pois é possível cuidar sem estarmos dentro de muros, casas e salas de atendimento. É o sujeito o tempo todo interagindo com você e com a cidade. Teutônico faz da cidade seu rizoma, com suas múltiplas possibilidades de conexões com as pessoas e com os lugares; é uma rede potente de vida. Nesse processo, não existem roteiros ou ensaios, é a forma espontânea de como Teutônico vai construindo seus platôs que geram intensidade e poder. Quando estamos caminhando e conversando pela cidade, essa forma de estar com o outro nos remete à clínica peripatética de Lancetti (2007). O pano de fundo é a cidade, acolhendo formas de cuidar dos sujeitos acometidos por algum transtorno mental. Essa clínica está muito mais preocupada com a preservação da singularidade de cada um.

Teutônico, em sua cartografia, foi dando pistas sobre si e o lugar que dava ao seu cuidador e às instituições. Em seus comportamentos, ele questionava as normativas instituídas de regulação da vida, o que apareceu mais na residência terapêutica. Demonstra sua insatisfação criando atritos, transgredindo, mostrando-se desafiador e rebelde; é a forma que buscou para expressar suas divergências e descontentamentos. É uma expressão de vida, estar na vida e pertencer a algum lugar.

Teutônico se constitui como um produtor de rede. Ele produz uma rede na qual faz conexōes com várias pessoas e instituiçōes, o que se torna referência para si. Chamo-as no estudo de platôs, lugares de referência e de intensidade produtiva.

A rede que Teutônico produz é uma rede de fluxos e conexões, na medida em que ela existe pela constância das atividades e de conexão com o mundo e com as pessoas. É uma rede que não tem forma, não tem lugar; existe, mas não é fixa, não é instituída, não é rígida, existe à medida que ele produz e dá sentido para sua vida.

Teutônico é produtor de redes, e essa atividade de produção de rede transgressora a normas é o que possibilita a sua existência produtiva e criativa. É 
um homem ativo e dinâmico, e a equipe acompanha suas produções, tentando minimizar os possíveis riscos produzidos por ele mesmo. É interessante pensar se as equipes de saúde mental têm condiçõos de lidar com esse sujeito múltiplo, heterogêneo, que produz redes transgressoras e desafiadoras, mas ao mesmo tempo redes de autonomia, de vínculos, sensíveis, orientadas em direção ao seu próprio cuidado.

\section{Considerações finais}

Com base na cartografia proposta neste estudo, foi possível acompanhar os processos, mais do que analisá-los e julgá-los. Esse percurso foi uma aproximação com o que estava acontecendo, permitindo desenhar algum caminho para aqueles que se debruçam sobre o lugar de cuidador. Gostaria de acrescentar que, qualquer que seja o trabalho, principalmente nesse universo da loucura, o desejo é a engrenagem para que se continue a caminhada como cuidador.

O achado da pesquisa que mais chama atenção é o fato de que o usuário pesquisado é um grande protagonista na construção de sua rede, do seu cuidado, criando, a partir disso, novas possibilidades de existência. Cria uma linha de fuga potente, ressignificando sua vida ao questionar, burlar e transgredir regras, seja no hospital psiquiátrico, no CAPS, nos quartos ou na residência terapêutica. Ao olhar do outro, esse usuário pode se mostrar inadaptado. Mas talvez o que nosso protagonista deseje seja a tentativa de construir relações e pontos de alta intensidade, através dos seus platôs. Ele se produz no mundo pelos seus platôs.

Percebe-se, assim, outra forma de pensar o cuidado em saúde mental, pois o que este caso deixa claro é a necessidade de criar espaços de maior entendimento das singularidades que se expressam no usuário e procurar atendê-lo nisso, o que é possível a partir de cuidados centrados em tecnologias mais relacionais, de abordagens acolhedoras e da escuta das subjetividades nômades, como a desse usuário.

O estudo informa que as redes no cuidado em saúde mental colocam o usuário em uma dobra. De um lado dela, há a rede institucional, que tem o seu papel nesse cuidado, dando referência, norma e disciplina sobre a vida do usuário; de outro, a rede singular, rizomática, construída no seu protagonismo. Nesse caso específico, Teutônico constrói nas suas conexões de rede uma outra cidade, 
microcosmo para si, que institui liberdade, potência de vida, subjetivações. A

dobra revela a presença das duas redes, em uma imanente tensão, que constitui o território existencial do usuário, de seus cuidadores e daqueles que produzem rede com os mesmos. É nesse complexo emaranhado que se produzem a vida e o cuidado, simultaneamente. Não há como atribuir um juízo de valor sobre as diferentes redes, se formais ou rizomáticas; cabe apenas o reconhecimento de que estas têm uma função no cuidado.

Ressaltamos o grande aprendizado com o caso, revelando que estudos como tal são potentes dispositivos para a pesquisa sobre a produção do cuidado. Isso porque se revela um processo vivo de produção do mundo e de si mesmo no emaranhado de possibilidades na saúde mental. A pesquisa abre uma janela de possibilidades de investigação e, por isso, fica a ideia de continuidade presente nesta conclusão. ${ }^{3}$

\section{Referências}

ALVES, D. S. Integralidade nas políticas de saúde mental. In: PINHEIRO, R.; MATTOS, R. A. (Org.). Os sentidos da integralidade na atenção e no cuidado à saúde. Rio de Janeiro: IMS-UERJ, 2001.

BEAKLINI, T. J. M. A proteção social na reestruturação da assistência em saúde mental: o programa de bolsa-auxílio do Hospital Psiquiátrico de Jurujuba, Niterói RJ. Dissertação (Mestrado em Saúde Pública) - Escola Nacional de Saúde Pública, Fundação Oswaldo Cruz, Rio de Janeiro, 2001.

BRASIL. Portaria n. 3.088, de 23 de dezembro de 2011. Institui a Rede de Atenção Psicossocial para pessoas com sofrimento ou transtorno mental e com necessidades decorrentes do uso de crack, álcool e outras drogas, no âmbito do Sistema Único de Saúde (SUS). Brasília: Ministério da Saúde, 2011. Disponível em: <http://bvsms.saude.gov.br/ bvs/saudelegis/gm/2011/prt3088_23_12_2011_rep.html>.

CAMARGO, Jr. K. R. de. Paradigma, ciência e saber médico. Rio de Janeiro: IMS-UERJ, 1992 (Série Estudos em Saúde Coletiva, 6).

CARVALHO, A. I. Política de saúde e organização setorial do país. Documento preparado para o curso à distância de especialização em Autogestão em Saúde. Rio de Janeiro: ENSP/ FIOCRUZ, 1999.

CORDEIRO, H. Sistema Único de Saúde. Rio de Janeiro: Ayuri, 1991.

DELEUZE, G. Espinosa: filosofia prática. São Paulo: Escuta, 2002. 
DELEUZE, G.; GUATTARI, F. Mil Platôs: capitalismo e esquizofrenia. V. I. São Paulo: Ed 34, 1995.

. O Anti-Édipo. Lisboa: Assírio e Alvim, 1972.

FRANCO, T. B. As redes na micropolítica do processo de trabalho em saúde. In: PINHEIRO, R.; MATTOS, R. A. Gestão em redes: práticas de avaliação, formação e participação na saúde. Rio de Janeiro: CEPESC, 2006.

FRANCO, T. B.; ANDRADE, C. S.; FERREIRA, V. S. C. A produção subjetiva do cuidado: cartografias da estratégia saúde da família. São Paulo: Hucitec, 2009.

FRANCO, T. B.; RAMOS, V. C (Org.). Semiótica, afecção e cuidado em saúde. São Paulo: Hucitec. 2010.

FRANCO T. B.; MERHY E. E. O reconhecimento de uma produção subjetiva do cuidado, Saúde Coletiva, Revista 19/02/2011. 2011.

FOUCAUlT, M. A. História da loucura. São Paulo: Perspectiva, 1972. . Microfísica do poder. Rio de Janeiro: Graal, 1979.

GUATTARI, F.; ROLNIK, S. Micropolitica: cartografia do desejo. 8a ed. Petrópolis: Vozes, 2007.

JOLY, F. A cartografia. 8a ed. Campinas: Papirus, 2005.

KASTRUP, V. O funcionamento da atenção no trabalho do cartógrafo. Psicologia e Sociedade. Porto Alegre, v. 19, n. 1, jan./abr. 2007.

LANCETTI, A. Clínica Peripatética. São Paulo: Hucitec, 2007.

MERHY, E. E. Saúde: cartografia do trabalho vivo. São Paulo: Hucitec. 2002. . Perspectivas atuais do SUS e agir tecnológico do trabalhador como um ato ético-politico.

In: CICLO DE DEBATES DO SERVIÇO SOCIAL DO HOSPITAL DAS CLÍNICAS DA UNIVERSIDADE ESTADUAL DE CAMPINAS, 20, Campinas-SP, 2003.

MERHY, E. E.; AMARAL, H. Reforma psiquiátrica no cotidiano. Campinas: Hucitec, 2007.

MERHY, E. E. et al. O trabalho em saúde: olhando e experienciando o SUS no cotidiano. São Paulo: Hucitec, 2003.

MERHY, E. E. et al. Redes Vivas: multiplicidades girando as existências, sinais da rua. Implicações para a produção do cuidado e a produção do conhecimento em saúde. Revista Divulgação em Saúde para Debate. Rio de Janeiro, n. 51, out. 2014.

PASSOS. S. E.; KASTRUP, V.; ESCÓSSIA, L. (Org.). Pistas do método da cartografia: pesquisa-intervenção e produção de subjetividade. Porto Alegre: Sulina, 2010.

ROLNIK, S. Cartografia sentimental. Porto Alegre: UFRGS, 2007. 
${ }^{1}$ Rizoma é uma figura da botânica, raiz que tem formato variável (ou é informe), crescimento horizontal, multiplicidade de movimento. O rizoma serve bem à figuração da rede. A grama é um exemplo de rizoma. Essa imagem é usada por Deleuze e Guattari (1995) para discutir o modelo de pensamento e práxis o qual serve à ideia de rede que não obedece a um fluxo normativo e organizado, mas que se realiza com base em múltiplas conexões, podendo assumir formas antes impensadas.

2 [...] intensidades buscam formar máscaras para se apresentarem, se "simularem"; sua exteriorização depende de elas tomarem corpo em matérias de expressão. (ROLNIK, 2007).

${ }^{3}$ M. N. Carvalho realizou a pesquisa, analisou os dados e redigiu a primeira versão do artigo. T. B. Franco orientou a pesquisa e a análise dos dados, supervisionou a redação do artigo e colaborou com a redação final. 


\section{Abstract}

\section{Mapping a user's paths of mental health services: his own production and the city's to deinstitutionalize}

Based on the mapping proposed in this study, we tried to analyze the mental health care network, taking a user as analyzer of his own network. The production data was observing the work and care setting, notes in a diary, user's monitoring and interviews with him and with his primary caregiver. The finding of the study that draws more attention is the fact that the user is a major player in building his network, his care, creating from it, new possibilities of existence and producing its own institutionalization, leading us to believe the construction of other cities in the world of madness is possible.

Key words: mental health; care; mapping; network. 